\title{
The use of natalizumab for multiple sclerosis
}

This article was published in the following Dove Press journal:

Neuropsychiatric Disease and Treatment

28 June 2017

Number of times this article has been viewed

\section{Rachel Brandstadter Ilana Katz Sand}

Department of Neurology, Corinne Goldsmith Dickinson Center for Multiple Sclerosis, Icahn School of Medicine at Mount Sinai, New York, NY, USA
Correspondence: Ilana Katz Sand Department of Neurology, Corinne Goldsmith Dickinson Center for Multiple Sclerosis, Icahn School of Medicine at Mount Sinai, $5 \mathrm{E}$ 98th St, Suite II 38, New York, NY, USA $\mathrm{Tel}+\mathrm{I} 2$ |2 24I 6854

Email ilana.katzsand@mssm.edu
Abstract: Natalizumab is a monoclonal antibody that acts as an $\alpha 4$ integrin antagonist to prevent leukocyte trafficking into the central nervous system. It is US Food and Drug Administration (FDA) approved for the treatment of relapsing-remitting multiple sclerosis (RRMS). Natalizumab demonstrated high efficacy in Phase III trials by reducing the annualized relapse rate, preventing multiple sclerosis (MS) lesion accumulation on magnetic resonance imaging, and decreasing the probability of sustained progression of disability. The leading safety concern with natalizumab is its association with progressive multifocal leukoencephalopathy (PML), a rare brain infection typically seen only in severely immunocompromised patients caused by reactivation of the John Cunningham virus (JCV). Careful analysis of risk factors for PML in natalizumab-treated MS patients, specifically the presence of anti-JCV antibodies, has led to risk mitigation strategies to improve safety. Additional biomarkers are under investigation to further aid risk stratification. Natalizumab's high efficacy and favorable tolerability profile have led to a broad use by MS physicians, as both firstand second-line treatments. This review discusses the natalizumab efficacy, safety, and tolerability and finishes with pragmatic considerations regarding its use in clinical practice.

Keywords: review, efficacy, safety, progressive multifocal leukoencephalopathy, JC virus, treatment

\section{Introduction}

Multiple sclerosis (MS) is a central nervous system (CNS) disorder that results in part from inflammatory injury and in part from neurodegeneration. Though the exact pathophysiology of this disease has not been fully elaborated, much is understood about the role of lymphocytes and the accompanying CNS inflammatory cascade that results in demyelination, neuronal damage, and, ultimately, neurological disability. Pathological evaluation has demonstrated a significant role for activated lymphocytes in MS lesions. ${ }^{1}$ Within the inflammatory milieu of MS, the brain, cerebrospinal (CSF) and blood lymphocyte levels are increased via clonal expansion of T-cell subsets., ${ }^{2,3}$ Accumulation of lymphocytes in the brain occurs via various methods of transmigration across the blood-brain barrier, making their entry point at the blood-brain barrier a valuable target for MS therapy.

In inflammatory states such as MS, endothelial cells that line postcapillary venules are activated by cytokines, and there is enhanced expression of numerous cell adhesion molecules (CAMs) on the vascular endothelium. These in turn enable tethering, rolling, and gripping of circulating lymphocytes to the endothelium, which prepares them for transmigration across the blood-brain barrier. ${ }^{4,5}$ Examples of these CAMs include P- and E-selectins, and vascular cell adhesion molecule-1 (VCAM-1). ${ }^{6-8}$ VCAM-1 acts as a ligand for $\alpha 4$ integrin receptors expressed mostly on lymphocytes, monocytes, and eosinophils. ${ }^{9-11} \alpha 4$ integrins are capable of forming heterodimers with two $\beta$-subunits $\left(\beta_{1}\right.$ and $\left.\beta_{7}\right)$ to form functional molecules. ${ }^{1}$ The association between VCAM-1 
and $\alpha 4$ integrin facilitates firm adhesion of lymphocytes to the endothelium, which in turn allows for transmigration of the lymphocytes. ${ }^{1}$ Furthermore, the interaction between the $\alpha 4$ integrin and VCAM- 1 transforms the phenotype of the lymphocyte causing activation ${ }^{12}$ and proliferation. ${ }^{13}$ There is a cascade of local cytokines and chemokines that then activate more lymphocytes and further promote adhesion and transmigration of these cells into inflamed tissue. ${ }^{14,15}$ A similar interaction occurs between the $\alpha 4$ integrin-expressing lymphocytes and extracellular matrix molecules such as fibronectin ${ }^{16}$ and osteopontin, ${ }^{17,18}$ which further propagates inflammation within the brain. Ascertainment of this mechanism led to a significant interest in $\alpha 4$ integrin as a target for disease-modifying therapy (DMT) for MS.

Research on the therapeutic potential of $\alpha 4$ integrin inhibitors was conducted in the murine model of MS, experimental autoimmune encephalomyelitis (EAE). ${ }^{19}$ Monocytic cell lines from humans, rats, and mice were found to selectively bind to inflamed vessels in brain sections from animals with EAE at day 5 after induction. Human peripheral neutrophils did not bind, as expected given their lack of $\alpha 4$ integrin receptors. Binding of human monocytes was nearly completely $(>95 \%)$ inhibited by pretreatment of the tissue sample with a monoclonal antibody to $\alpha 4$ integrin. Intraperitoneal injection of this same antibody 2 days after induction of EAE prevented the paralysis of the experimental animals and reduced the severity of paralysis in animals that did ultimately develop EAE.

Antibodies to $\alpha 4$ integrin were found to block both $\alpha 4 \beta_{7}$ and $\alpha 4 \beta_{1}$ heterodimers. The $\alpha 4 \beta_{7}$ molecule plays a role in the migration of $\mathrm{T}$ cells in the gut; thus, these monoclonal antibodies were purposed for the treatment of the inflammatory bowel disease, Crohn's disease. The $\alpha 4 \beta_{1}$ molecule (also known as the very late antigen 4 or VLA4) was found to play a dominant role in EAE development, and thus $\alpha 4$ integrin inhibitors moved forward into human trials for the treatment of MS.

\section{Natalizumab efficacy Clinical efficacy in relapsing-remitting multiple sclerosis}

Natalizumab (Tysabri ${ }^{\circledR}$; Biogen Idec/Elan, Cambridge, MA, USA) is the first $\alpha 4$ integrin antagonist created for the treatment of MS. Two pivotal randomized, double-blinded placebo-controlled Phase III trials supported the US Food and Drug Administration (FDA) approval of natalizumab for the treatment of relapsing-remitting multiple sclerosis (RRMS), and the results are summarized in Table 1. The Natalizumab Safety and Efficacy in Relapsing-Remitting
Multiple Sclerosis (AFFIRM) study enrolled 942 RRMS patients, with at least one documented relapse in the prior year, from 99 clinical centers across Europe, North America, Australia, and New Zealand. ${ }^{20}$ Subjects were randomly assigned to receive natalizumab $300 \mathrm{mg}$ intravenously every 4 weeks or placebo infusion. At 1 year, the primary outcome was annualized relapse rate (ARR), and at 2 years, the primary outcome was the cumulative probability of sustained progression of disability, defined as an increase of $\geq 1.0$ on the Expanded Disability Status Scale (EDSS) from a baseline score of $\geq 1.0$ or an increase of $\geq 1.5$ from a baseline score of 0 that was sustained for 12 weeks. Secondary analyses at both time points included magnetic resonance imaging (MRI) efficacy data and progression of disability as measured by the Multiple Sclerosis Functional Composite (MSFC). As compared to placebo, the treatment group showed a $68 \%$ reduction in ARR at 1 year (0.26 in the natalizumab group vs 0.81 in the placebo group, $P<0.001)$ and a $42 \%$ reduction of the risk of confirmed disability worsening at 2 years $(17 \%$ vs $29 \%, P<0.001)$. The proportion of relapse-free patients was significantly higher in the natalizumab group compared with the placebo group at 1 year $(77 \%$ vs $56 \%, P<0.001)$.

Treatment with natalizumab reduced the mean number of new or enlarging T2 hyperintense MRI lesions over 2 years by $83 \%$ (mean of $1.9 \pm 9.2$ lesions for natalizumab patients vs $11.0 \pm 15.7$ lesions in placebo patients, $P<0.001) .{ }^{20}$ Fiftyseven percent of patients treated with natalizumab developed no new or enlarging T2-hyperintense lesions over the 2-year study period compared with $15 \%$ of placebo patients. ${ }^{20}$ Natalizumab also decreased the mean number of lesions detected by gadolinium-enhanced MRI by $92 \%$ at both 1 and 2 years. ${ }^{20}$ Ninety-seven percent of natalizumab patients had no gadolinium-enhancing lesions on the year 2 MRI scan versus $72 \%$ of placebo patients $(P<0.001) .{ }^{20}$ In addition, the mean number of new T1-hypointense lesions over 2 years was 1.1 in the natalizumab group and 4.6 in the placebo group, a $76 \%$ reduction $(P<0.001){ }^{21}$ The mean percentage of reduction in brain parenchymal fraction (BPF), a marker of brain atrophy, was similar between groups $(P=0.822){ }^{21}$

The Safety and Efficacy of Natalizumab in Combination with Interferon Beta-1a in Patients with Relapsing-Remitting Multiple Sclerosis (SENTINEL) study was also a 2-year Phase III trial that was similarly designed to AFFIRM. ${ }^{22}$ A total of 1,171 RRMS patients across 123 clinical centers in Europe and the United States were randomized to receive either a combination of natalizumab $300 \mathrm{mg}$ intravenously every 4 weeks plus interferon (IFN) beta-1a $30 \mu \mathrm{g}$ via intramuscular injection weekly or placebo infusion 


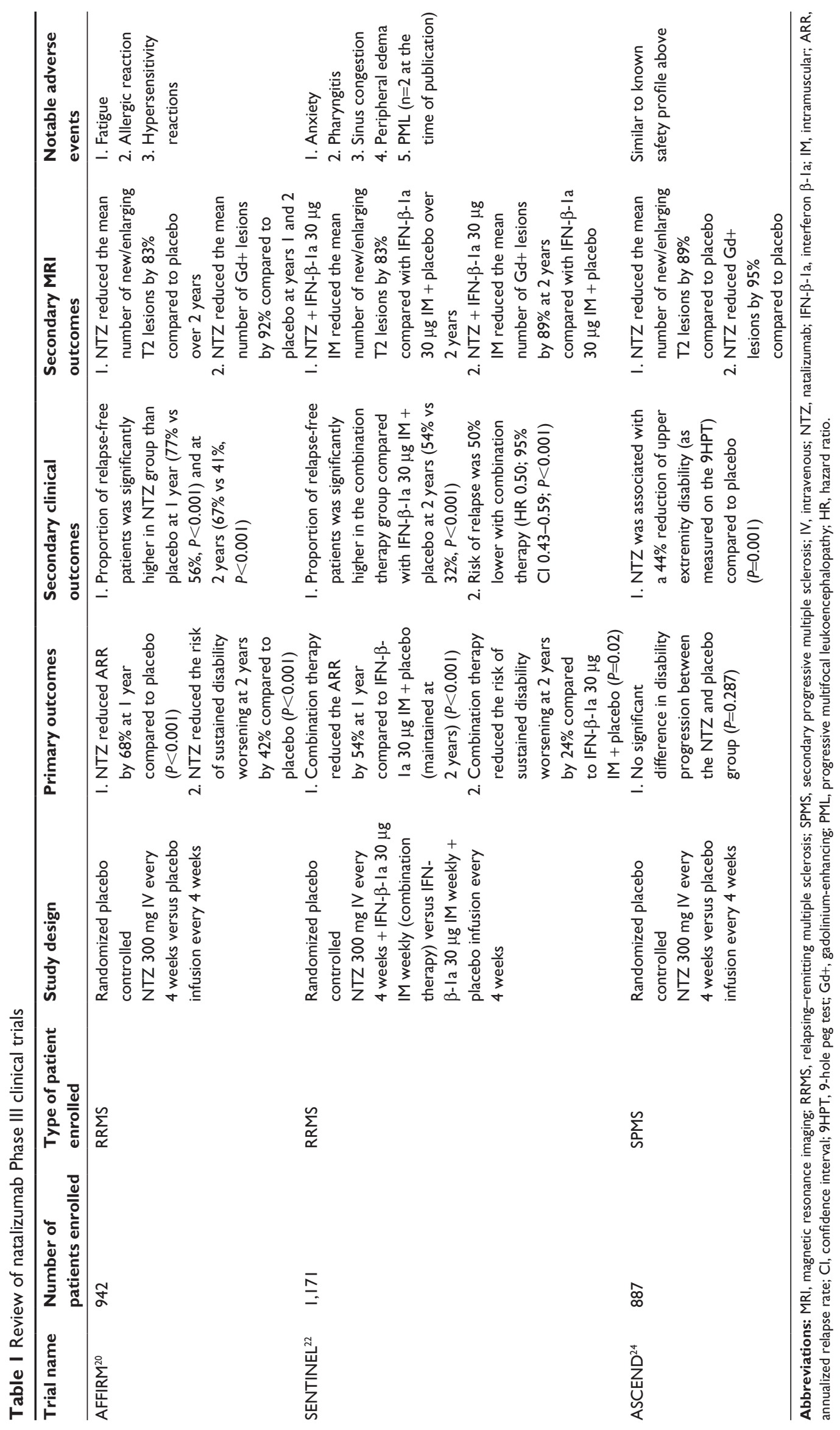


every 4 weeks plus IFN beta-1a $30 \mu \mathrm{g}$ via intramuscular injection weekly. Eligible subjects had at least one clinical relapse in the 12-month period leading up to study start while on IFN beta-1a therapy alone. As in the AFFIRM trial, the primary endpoint was the rate of clinical relapse at 1 year. Secondary outcomes at 1 year included the number of new or enlarging T2-hyperintense lesions, the number of gadolinium-enhancing lesions, and the proportion of patients free of relapse. Again, the primary outcome at 2 years was the cumulative probability of sustained disability progression, defined as an increase by at least 1.0 point in the EDSS score from a baseline score of at least 1.0 or an increase by at least 1.5 points in the EDSS score from a baseline score of 0 , sustained for 12 weeks. After 1 year, the ARR for natalizumab combination therapy was 0.38 compared with 0.82 for IFN beta-1a alone, a 54\% reduction in the relapse rate $(P<0.001)$. This effect was durable at 2 years, with ARR of 0.34 in the combination therapy group compared with ARR of 0.75 in the placebo group at year $2(P<0.001)$. Patients on the combination of natalizumab and IFN beta-1a were less likely to have sustained disability progression at 12 weeks than those on IFN beta-1a alone ( $23 \%$ vs $29 \%$, respectively, $P=0.02$ ), representing a $24 \%$ decrease in the risk of sustained disability progression on combination therapy. Estimates of sustained disability progression at 24 weeks were not statistically significant between the two treatment groups $(P=0.17)$. With respect to imaging, there was an $83 \%$ reduction in the number of new or enlarging T2-hyperintense lesions over a 2-year period in the natalizumab combination therapy group compared with the IFN beta-1a alone group. ${ }^{22}$ SENTINEL also demonstrated an $89 \%$ reduction in gadolinium-enhancing lesions in the natalizumab group. ${ }^{22}$

An Italian single-center retrospective study examined 152 RRMS patients who began natalizumab therapy between February 2007 and October 2008 and examined their longterm outcomes to determine how many patients maintained their status of no evidence of disease activity (NEDA). ${ }^{23}$ NEDA was defined as absence of relapses, absence of sustained disability worsening (described as $\geq 1.0$ point increase on EDSS confirmed at 6 months), and absence of radiographic activity (gadolinium-enhancing lesions or new/ enlarged T2-hyperintense lesions). In this cohort, 58 of the original 152 patients were still on natalizumab treatment after 7 years and 94 had discontinued treatment after a median time of 3 years. When analyzed with an intentionto-treat model, 52 (34\%) patients maintained NEDA by the end of the 7-year follow-up. This number increased to $41 \%$ of patients maintaining NEDA status when excluding the
64 patients who discontinued natalizumab due to concerns about potential progressive multifocal leukoencephalopathy (PML). The authors compared this rate to previous studies showing rates of long-term clinical stability in $<10 \%$ of patients on injectable therapies.

\section{Clinical efficacy in secondary progressive multiple sclerosis}

Because of the noted effects on disability progression in the relapsing-remitting trials, natalizumab was studied in progressive disease through the Clinical Study of the Efficacy of Natalizumab on Reducing Disability Progression in Participants With Secondary Progressive Multiple Sclerosis (ASCEND in SPMS) trial. ${ }^{24}$ Results from this trial are summarized in Table 1. Patients with secondary progressive multiple sclerosis (SPMS) were randomized to $300 \mathrm{mg}$ of intravenous natalizumab every 4 weeks $(n=439)$ or to placebo $(n=448)$ for up to 96 weeks. Eligible participants had an EDSS score of 3.0-6.5 and documented confirmed evidence of disease progression independent of clinical relapses within the year prior to enrollment. Most subjects had advanced disability as reflected by a mean EDSS score of 6.0-6.5 (requiring assistance to walk), and $71 \%$ of patients had been relapse free for $\geq 2$ years prior to enrollment. The primary endpoint was confirmed disability progression on one or more disability assessments: EDSS, timed 25-foot walk (T25FW), or 9-hole peg test (9HPT) (a measurement of upper-extremity disability). At 2 years, there was no statistically significant difference between the two groups with respect to disability progression. The proportion of patients who progressed in the placebo group was $48 \%$ as compared with $44 \%$ in the natalizumab group $(P=0.287)$. It is worth noting that there was a significant difference found in the performance on the 9HPT between groups, with $15 \%$ worsening in the natalizumab group and $23 \%$ worsening in the placebo group $(P=0.001)$. Nevertheless, the ASCEND trial failed to show major efficacy of natalizumab for SPMS.

\section{Natalizumab safety and tolerability Progressive multifocal leukoencephalopathy}

The leading safety concern associated with natalizumab is PML, which is an uncommon and severe opportunistic brain infection caused by reactivation of a common polyomavirus, the John Cunningham virus (JCV). JCV, present in $\sim 50 \%-70 \%$ of the population ${ }^{25}$ as evidenced by the presence of serum JCV antibodies, may remain asymptomatic in the kidneys and possibly the lymphoid organs throughout life..$^{26,27}$ 
In selected circumstances, the JCV can become neurotropic and cause PML and demyelination of axons as a consequence of lytic infection of the myelin-producing oligodendrocytes. PML may present clinically with cognitive, motor, sensory or visual field deficits, aphasia, incoordination, and/or gait disturbance. MRI classically shows hyperintense lesions on T2-weighted and fluid-attenuated inversion recovery (FLAIR) images with hypointensity seen on T1-weighted images. PML lesions typically do not show contrast enhancement, but some reports suggest that up to $40 \%$ of natalizumab-associated PML cases have demonstrated contrast enhancement. ${ }^{28-31}$ Lesions are often multifocal and found in the frontal and parieto-occipital regions of the brain, though there may be solitary lesions found anywhere in the brain. ${ }^{31}$ Diagnosis is made based on history, imaging, and CSF analysis with polymerase chain reaction (PCR) testing for JCV. The JCV PCR assay has a high sensitivity, but a negative PCR does not completely rule out PML. ${ }^{31}$ At times, brain biopsy with PCR amplification of brain tissue is needed to clarify diagnosis. ${ }^{31}$

The prognosis for PML is often grim, with a high fatality rate. PML is exceedingly rare, occurring in only 0.2 per 100,000 of the general population. ${ }^{25}$ The risk of PML becomes significant when a patient is immune compromised as with AIDS, malignancy, or use of immunosuppressive therapy. Therefore, it has been speculated that PML occurs when CNS immunosurveillance is weakened. ${ }^{32} \mathrm{MS}$ alone does not confer a higher risk of PML than the general population; however, certain MS therapies have been associated with an increase in PML risk, including natalizumab. ${ }^{33}$ The SENTINEL study was halted 1 month early on February 28, 2005, due to reports of PML in natalizumab-treated patients. One of these patients was enrolled in SENTINEL and another was participating in an open-label safety study of natalizumab and IFN beta-1a after completing SENTINEL. A third PML patient was discovered after postmortem analysis of a natalizumab-treated patient with Crohn's disease who had mistakenly received a diagnosis of astrocytoma. Not only was the SENTINEL study suspended, but the drug was also temporarily removed from the market. A global risk-management program was then created to develop a risk stratification paradigm for PML.

Initial investigation revealed three major risk factors for the development of PML, including a positive anti-JCV antibody (via a two-step enzyme-linked immunosorbent assay [ELISA] by STRATIFY JCV; Focus Diagnostics, Cypress, CA, USA), prior use of immunosuppressants, and increased duration of natalizumab treatment. ${ }^{34}$ Data from the Biogen Idec global safety database, from clinical studies (including AFFIRM, ${ }^{20}$ STRATIFY $-1^{35}$ ), and from the Tysabri Global Observational Program in Safety study (TYGRIS ${ }^{35}$ ) were used initially to confirm these risk factors. Bloomgren et al examined this data and information from an independent Swedish registry of patients with MS to assess the PML risk. ${ }^{34}$ These authors found that among a total of 5,896 patients from AFFIRM, TYGRIS-U.S., and STRATIFY-1, the prevalence of anti-JCV antibodies was 54.9\% (95\% CI 53.7-56.2\%). They noted that the prevalence of anti-JCV antibodies increased with age and was higher in men. The investigators identified 212 confirmed cases of PML among 99,571 patients treated with natalizumab, for an overall risk of 2.1 cases per 1,000 patients. Fifty-four of these patients had pre-PML diagnosis JCV antibody samples available for analysis. There were no significant demographic differences between the 54 PML patients analyzed and the rest of the studied cohort without PML. All of these 54 patients tested positive for anti-JCV antibodies. In this analysis, the greatest risk of PML was found to be in patients receiving $>2$ years of natalizumab therapy. However, data beyond 4 years of treatment were limited at the time of analysis. The investigators also discovered that $34.5 \%$ of natalizumab-treated patients with PML had been previously treated with one or more immunosuppressant (mitoxantrone, methotrexate, azathioprine, cyclophosphamide, and mycophenolate mofetil); as compared with $20.3 \%$ of all natalizumab-treated patients in the TYGRIS study. The duration of prior immunosuppressive therapy and the type of therapy varied widely in the PML patients. Of note, traditional MS therapies available at the time (IFN and glatiramer acetate) were not qualified as immunosuppressive based on the mechanism of action and do not seem to confer the same increased risk of PML.

The incidence of PML among patients with positive anti-JCV antibodies in this cohort was 3.87 cases per 1,000 treated (95\% CI 2.91-5.05). ${ }^{34}$ Patients were then stratified according to the presence or absence of the three identified risk factors. In the highest risk group (positive anti-JCV antibody test, duration of therapy 25-48 months, and prior immunosuppressant use), the estimated incidence of PML was 11.1 cases per 1,000 patients (95\% CI 8.3-14.5). For patients with positive anti-JCV antibody tests with no prior immunosuppressant use, the estimated incidence of PML was 0.56 per 1,000 patients in those who received $1-24$ months of natalizumab exposure and 4.6 per 1,000 patients in those with 25-48 months of natalizumab exposure. It was not possible to ascertain the incidence of PML among patients with a negative anti-JCV antibody test because in this data set there were no patients with PML who tested negative. 
By performing sensitivity analysis with one hypothetical PML patient with negative anti-JCV antibodies, the authors calculated a risk of $\leq 0.09$ cases per 1,000 patients $(95 \% \mathrm{CI}$ $0-0.48)$ in antibody-negative patients. Last, the investigators noted a low annual seroconversion rate from a negative to a positive anti-JCV antibody at $\sim 2 \%$.

The STRATA MS study ${ }^{36}$ was a prospective, observational open-label study evaluating the long-term safety and efficacy of natalizumab over 240 weeks of therapy in 1,094 patients. This study calculated the cumulative incidence of PML to be as high as 12.8 per 1,000-natalizumab treated patients. ${ }^{36}$ Another large prospective study, STRATIFY-2, confirmed the rate of PML in anti-JCV antibody-negative patients to be 1 per 10,000 patients. ${ }^{37}$ Plavina et al published a retrospective analysis of anti-JCV antibody levels in an attempt to further characterize the risk of PML in patients with positive JCV antibody status. ${ }^{38}$ They analyzed the samples of patients from AFFIRM, STRATIFY-1, STRATIFY-2, and postmarketing sources. They found a higher JCV antibody index value in pre-PML samples from natalizumabtreated patients who ultimately went on to develop PML $(\mathrm{n}=71)$ than in samples from anti-JCV antibody-positive patients who did not develop PML $(n=5,834)$ (median of 2.4 vs $1.4, P<0.0001)$. Though this difference was maintained for patients with no prior immunosuppressant use, the index value distribution was similar for non-PML and PML patients with prior immunosuppressant use (median 1.6 in both groups, $P=0.82$ ). This group found that for anti-JCV antibody-positive patients with no prior immunosuppressant use and an anti-JCV antibody index $\leq 0.9-1.5$, the risk of PML was $\sim 0.1$ per 1,000 patients during the first 2 years of treatment. This value was felt to be similar to patients with JCV antibody-negative tests. For this low-index value group, the risk of PML was calculated in a range of 0.3-1.3 per 1,000 patients from months 25 to 48 and from months 49 to 72 of therapy. Patients with no prior immunosuppressant use and an index value of $>1.5$ were found to have the greatest measured PML risk, measured at $\sim 1$ per 1,000 patients during the first 2 years of treatment, and ranging from 8.1 to 8.5 per 1,000 patients from months 25 to 48 and from months 49 to 72 of treatment. The authors suggested that the index value be used to safely identify patients with positive antibody tests who have a low risk for PML.

Subsequent analyses of this data have been performed and different estimations have been published regarding the risk of PML as it relates to JCV antibody titers. Borchardt and Berger issued their opinion that the prior risk estimates drastically underestimate the risk of PML. ${ }^{39}$ These authors utilized
Kaplan-Meier curves and other techniques to estimate the risk of PML. They found the overall incidence of PML to be $1.3 \%$ during the first 24 months of natalizumab therapy and to be $6.8 \%$ at 48 months of therapy. They extrapolate that the risk of PML for months 25 to 48 in all patients on therapy is $5.51 \%$. In a more detailed analysis, they report an estimated risk of PML in JCV antibody-positive patients without prior immunosuppressant use between months 25 and 48 to be $7.4 \%$ (compared with $5.3 \%$ reported by Biogen) and between months 49 and 72 to be $10.8 \%$ (compared with $6.1 \%$ reported by Biogen).

Though JCV antibody testing has been useful in estimating the danger of PML in MS patients on natalizumab, there are clearly weaknesses with using this test alone. As such, investigators have sought additional methods to better predict PML risk. One such biomarker is a lymphocyte CAM, L-selectin (CD62L). Though its pathophysiologic role in MS is not fully understood, L-selectin is thought to mediate myelin damage in the CNS ${ }^{40,41} \mathrm{~L}$-Selectin is a CAM present on the surface of most circulating lymphocytes ${ }^{42}$ and is normally shed in the serum from the surface of lymphocytes after the initial tethering of the lymphocyte to the endothelium; however, shedding can also occur prematurely during cross-linking with certain monoclonal antibodies like natalizumab. ${ }^{43-45}$ This may explain mechanistically how activated lymphocytes are then unable to re-enter the peripheral lymph nodes or other sites of inflammation without the L-selectin molecule. ${ }^{40,46,47} \mathrm{~L}$-Selectin is functionally active in the soluble form in the blood, ${ }^{48}$ and its levels are increased during acute or chronic inflammation. ${ }^{49}$ Basnyat et al examined a group of 99 subjects (44 RRMS patients treated with natalizumab, 30 RRMS patients treated with varying doses of IFN-beta, and 25 healthy controls) to study the levels of soluble L-selectin in the serum as measured by ELISA and the anti-JCV antibody index as measured by secondgeneration ELISA (STRATIFY JCV ${ }^{\text {TM }}$ DxSelect ${ }^{\mathrm{TM}}$ ). ${ }^{42}$ They found a significant correlation between the levels of soluble L-selectin and anti-JCV antibody indices in the sera of the natalizumab-treated patients ( $r=0.402, P=0.0007)$ but not in the other patients treated with IFN-beta. Levels of soluble L-selectin in the serum were significantly higher in the group of patients with high anti-JCV antibody index of $\geq 1.5$.

Recently, a group analyzed data from the Biomarkers and Response to Natalizumab for Multiple Sclerosis Treatment (BIONAT) cohort to test the viability of L-selectin as a risk stratification method for PML. ${ }^{50,51}$ A total of 1,220 patients were examined, and 11 of the 14 PML cases diagnosed in the cohort were included in this analysis. After 2 years of 
natalizumab exposure, cellular L-selectin expression was noted to be significantly lower in patients who later developed PML. In this retrospective analysis, a cutoff value of $10 \%$ of $\mathrm{L}$-selectin on $\mathrm{CD}^{+} \mathrm{T}$ cells provided the best balance between sensitivity (80\%; 95\% CI 41\%-97\%) and specificity $(85 \%$; 95\% CI $76 \%-89 \%)$ with a hazard ratio up to $7(95 \%$ CI $1.8-27, P=0.005)$. In their prospective cohort of 358 natalizumab-treated patients, cellular L-selectin levels were associated with the number of natalizumab infusions, with a decrease noted until 2 years of therapy with a subsequent increase in the value thereafter. The best time point for predicting PML was at 26 infusions in the BIONAT cohort. Similar results were not established during the analysis of samples from 21 natalizumab-treated patients with PML who were part of Biogen clinical trials. ${ }^{52}$ The authors who analyzed the BIONAT cohort account for this difference in findings by noting that the samples tested in the Biogen cohort occurred at an average number of $52 \pm 5.57$ infusions, at which point the levels of cellular L-selectin naturally begin to increase again. Larger prospective studies are needed in order to better elucidate the role of L-selectin in the risk stratification process of MS patients on natalizumab.

A multicenter study in Spain examined the presence of lipid-specific immunoglobulin $\mathrm{M}$ oligoclonal bands in the CSF, a marker found in highly inflammatory MS disease, as a predictive factor for PML. ${ }^{53}$ They studied $24 \mathrm{MS}$ patients who developed PML and 343 who did not. They discovered that IgM bands were independently associated with decreased PML risk in patients on natalizumab (odds ratio $[\mathrm{OR}]=45.9$; 95\% CI 5.9-339.3; $P<0.0001)$. Patients with CSF IgM bands and positive anti-JCV antibodies had similarly reduced PML risk to those patients who were merely anti-JCV antibody negative (OR $=1.55 ; 95 \% \mathrm{CI} 0.09-25.2 ; P=1.0)$. The highest risk of PML was found in the group of patients who were positive for anti-JCV antibodies and negative for CSF IgM bands (OR $=59.71 ; 95 \%$ CI 13.6-262.2). The authors speculate that the presence of IgM bands is reflective of an aggressive inflammatory process that may diminish the risk of PML. ${ }^{45}$

Some clinicians have attempted to lower the risk for PML by extending the dosing interval of natalizumab past the usual every 4-week administration. Standard dosing maintains maximal $\alpha 4 \beta_{1}$ integrin receptor saturation, defined as $>80 \%$ saturation of these receptors on the surface of lymphocytes. ${ }^{22}$ More than 8 weeks postadministration, serum natalizumab levels fall below $1 \mu \mathrm{g} / \mathrm{mL}$, and this results in $\alpha 4 \beta_{1}$ receptor desaturation, defined as saturation $<50 \%{ }^{54}$ Extended interval dosing (EID) of natalizumab is an attempt to target a level of $\alpha 4 \beta_{1}$ receptor saturation that maintains drug clinical effectiveness with the least effect possible on immunosurveillance in order to lower the PML risk. A retrospective chart review examined outcomes for 905 patients on EID versus 1,099 patients on standard interval dosing (SID). ${ }^{55}$ In this analysis, EID ranged from dosing every 4 weeks 3 days to dosing every 8 weeks 5 days. There were no significant differences in the two groups with respect to ARR, MRI activity, and percentage of patients who achieved no evidence of MS disease activity, though there was a significant difference with respect to JCV status $(50 \%$ positive in the SID group and $63 \%$ positive in the EID group, $P<0.05$ ). While four patients developed PML in the SID cohort, zero patients developed PML in the EID cohort. However, this was a retrospective analysis, and it was not powered adequately to achieve a statistically significant PML risk reduction. More data are being collected to enhance the understanding of the risks and benefits of EID through the EXTEND registry through MSBase. ${ }^{55}$

Certain factors have been found to be associated with poor outcome in PML patients including older age, high pre-PML disability, high number of CSF JCV copies, MRI findings demonstrating multifocal areas of involvement, and worse Karnofsky Performance Scale scores at the time of PML diagnosis. ${ }^{56}$ The rarity and severity of the condition as well as the lack of a targeted antiviral against JCV translate into a lack of rigorous prospective studies for the treatment of natalizumab-associated PML. Though not prospectively studied, clinicians have employed plasma exchange (PLEX) in order to facilitate natalizumab clearance and to restore normal immunosurveillance of the brain previously impaired by natalizumab. ${ }^{57}$ However, there is a demonstrated risk of immune reconstitution inflammatory syndrome (IRIS) after PLEX, which can cause further inflammatory brain damage. There are small case series showing the efficacy of maroviroc (a CCR5 antagonist) for the treatment of PML-IRIS. ${ }^{58,59}$ A more detailed discussion regarding the approach to treatment of natalizumab-associated PML is beyond the scope of this review but is available elsewhere. ${ }^{54,57,60,61}$

In order to remain vigilant about the risk for PML in natalizumab-treated MS patients, the drug is now administered through a risk mitigation program. ${ }^{62}$ The TOUCH program ensures that providers, infusion centers, and patients are educated about the risk of PML and works to promote risk-benefit awareness in the prescribing of natalizumab. ${ }^{62}$

\section{Other safety and tolerability issues}

The most frequent side effects reported in natalizumabtreated MS patients in clinical trials (incidence $\geq 10 \%$ ) include 
headache, urinary tract infection, lung infection, myalgias, vaginitis, abdominal pain, arthralgias, depression, diarrhea, rash, and nausea though all these symptoms occurred with a similar rate in placebo-treated patients. ${ }^{62}$ Fatigue and allergic reaction occurred more commonly in natalizumab-treated patients compared with placebo $(P=0.048$ and $P=0.012$, respectively). ${ }^{20}$ In the AFFIRM trial, serious adverse events occurred in $19 \%$ of patients treated with natalizumab and in $24 \%$ of patients receiving placebo $(P=0.06) .{ }^{20}$ These events included MS clinical relapse (6\% with natalizumab and $13 \%$ with placebo), cholelithiasis ( $<1 \%$ with both natalizumab and placebo), and the need for rehabilitation therapy $(<1 \%$ with both natalizumab and placebo). ${ }^{20}$ There were two deaths in the AFFIRM study, both of which were in the natalizumab group and were attributed to melanoma and alcohol intoxication. ${ }^{20}$ Two deaths in the SENTINEL trial both occurred in the placebo group. ${ }^{22}$ Infections seen in both groups were generally mild to moderate in severity and were most commonly nasopharyngitis, influenza, upper respiratory tract viral infection, and pharyngitis. ${ }^{20}$ Serious infections in AFFIRM were recorded in $3.2 \%$ of patients in the natalizumab group and $2.6 \%$ of the placebo-treated group, which did not reach the level of statistical significance. ${ }^{20}$ In the SENTINEL study, there was no significant difference between the rate of infections and infusion reactions between the two groups. ${ }^{22}$ Post-marketing studies of natalizumab have revealed a small number of cases of Herpes Simplex Virus (HSV) meningitis ${ }^{63}$ and encephalitis ${ }^{64,65}$ and reactivation of Varicella Zoster virus. ${ }^{66}$

Infusion-related reactions were defined as any adverse event occurring within 2 hours of the start of an infusion. ${ }^{62}$ In MS clinical trials, infusion reactions were seen in $\sim 24 \%$ of natalizumab-treated patients compared with $18 \%$ of placebo-treated patients. ${ }^{62}$ The most common infusion-related symptoms in natalizumab-treated MS patients were headache, dizziness, fatigue, urticaria, pruritis, and rigors. Approximately $2 \%$ of natalizumab-treated MS patients experienced acute urticaria and other hypersensitivity reactions were seen in $1 \%$ of these patients. ${ }^{62}$ In the AFFIRM trial, 25 patients receiving natalizumab had 27 hypersensitivity reactions, five of which included anaphylactic or anaphylactoid reactions. ${ }^{20}$ Fifty-seven patients from the AFFIRM trial given natalizumab $(9 \%)$ were found to have detectable antibodies to natalizumab and in those with persistent antibodies there was an increase in infusion-related adverse events and loss of efficacy of the drug. ${ }^{20}$ Anti-natalizumab antibodies were neutralizing in vitro, and their presence was associated with a reduction in serum natalizumab levels. ${ }^{62}$ Infusion-related reactions most often seen in patients with persistent antibody positivity included urticaria, rigors, nausea, vomiting, headache, flushing, dizziness, pruritus, tremor, feeling cold, pyrexia, myalgia, hypertension, dyspnea, anxiety, and tachycardia. ${ }^{62}$ Patients with documented anti-natalizumab antibodies should be discontinued from therapy. ${ }^{67}$

Complete blood count and liver function tests of the patients should be periodically monitored while on natalizumab. Increases in the number of lymphocytes, monocytes, eosinophils, and basophils are seen in natalizumab-treated patients, though as expected, neutrophils are not affected due to the absence of $\alpha 4$ integrin receptors. ${ }^{9-11,20}$

\section{Reproductive considerations}

Natalizumab is registered as pregnancy category $\mathrm{C}$ and thus should not be administered to patients who are pregnant, planning to become pregnant, or to those who are breastfeeding. Animal studies have demonstrated transplacental crossing of natalizumab with potential for fetal harm, including reduced pup survival in guinea pig studies and mild anemia or thrombocytopenia in monkeys with supratherapeutic doses of natalizumab. The Tysabri Pregnancy Exposure Registry prospectively enrolled 369 patients with MS and seven patients with Crohn's disease on natalizumab or with natalizumab exposure within 3 months of conception. Threehundred and fifty five of the enrolled patients had known pregnancy outcomes. ${ }^{68}$ This observational study yielded a major birth defect rate of 5.05\% (95\% CI 2.9\%-8.1\%) in natalizumab-exposed patients, which was higher than that seen in the general population as calculated by the Metropolitan Atlanta Congenital Defects Program (MACDP), but no specific pattern of malformation was found. The spontaneous abortion rate in pregnant women exposed to natalizumab in this registry was similar to that of the general population. ${ }^{68}$ Natalizumab has been detected in the breast milk, and the exposure effects on the baby are unknown. ${ }^{62}$ It is not generally recommended to breastfeed while on natalizumab.

\section{The use of natalizumab in clinical practice When to consider natalizumab initiation}

The decision regarding the choice of DMT in MS is often challenging and requires a highly individualized discussion between patient and provider that considers the potential benefits and risks of each option in the context of that patient's MS disease course. Though there have not been head-to-head randomized trials demonstrating superiority to other agents, natalizumab is generally accepted as a high-efficacy therapy for MS and is very well-tolerated. It therefore remains a 
desirable therapy despite the risk of PML. Its initial use was mainly as a second-line therapy for patients who failed injectables (IFN and glatiramer acetate), and certainly it is still used in this way today as part of "escalation" strategy. This is safest in patients who are negative for JCV antibody, but some MS experts also consider escalating to natalizumab in patients who are positive for JCV antibody (and who have not previously been treated with immunosuppressants) with the plan to limit the number of infusions and change the therapy at some point in the future. This strategy may not be without its own risks, separate from PML (see the section on natalizumab discontinuation below). In addition, because the risk for PML in JCV antibody-negative patients is exceedingly small, many MS experts offer the use of natalizumab as a first-line therapy, especially, though not exclusively, for patients with an aggressive presentation.

\section{Monitoring during treatment with natalizumab}

The annual rate of seroconversion from JCV antibody negative to positive varies in the literature, and it seems likely that therapy with natalizumab increases the seroconversion rate. ${ }^{34,51,69}$ It is therefore prudent to periodically repeat JCV antibody testing in patients who are initially negative. Most practitioners do this at least every 6 months. Because studies remain preliminary, there is a lack of consensus in the field regarding the utility of the JCV antibody index in routine clinical practice. However, among those practitioners willing to use natalizumab in patients who are initially positive or become positive for JCV antibody, some will periodically check the index to ensure that it remains in the putatively lowrisk range. Periodic monitoring for blood count and hepatic function are generally completed every 3 months.

For various practitioners, MRI of patients on natalizumab is generally checked at least yearly in JCV antibodynegative patients and at least every 6 months in positive patients. For those who are JCV antibody positive and have a compelling reason to continue natalizumab past the 1- to 2-year mark, or for those who are early in their natalizumab course but have a high index value, it is reasonable to increase the frequency of imaging to once every 3 months to evaluate for early signs of PML.

\section{When to consider natalizumab discontinuation}

There are several potential scenarios that warrant consideration for discontinuing natalizumab, mostly related to a change in the risk-benefit ratio for continued use of the drug.
As described, some practitioners may start a patient who is known to be JCV antibody positive on natalizumab with the knowledge that the risk of PML will at some point outweigh the benefit to staying on natalizumab. Precisely when this threshold is reached varies by risk tolerance level of the individual patient and practitioner as well as by the clinical context. Considered factors include the frequency and severity of exacerbations, disability level, previous therapies the patient has failed or not tolerated, and the patient's eligibility status regarding other high-efficacy therapies for MS. These same considerations apply to a patient who is initially negative for JCV antibody but seroconverts during the treatment course. Consideration may also be given to EID, but evidence for this remains very preliminary at this time.

As with any MS therapy, discontinuation should be considered if efficacy is suboptimal. An overall discussion of when to switch therapies for efficacy reasons is beyond the scope of this review; however, the general principle relates to the establishment of an ongoing pattern of disease activity. Natalizumab must also be discontinued in the case of allergic reactions and severe laboratory abnormalities or if the patient desires to become pregnant.

\section{Potential issues with natalizumab discontinuation}

As discussed, there are multiple potential clinical scenarios that mandate natalizumab discontinuation. There has been concern about the potential for worsening of clinical severity after cessation of natalizumab, including increased relapse rate, relapse severity, ${ }^{70}$ and number of new $\mathrm{T} 2^{71}$ and gadolinium-enhancing ${ }^{70,72}$ lesions, possibly attributable to an IRIS-like phenomenon. ${ }^{72,73}$ Most investigations show that the return of disease activity occurs relatively early after natalizumab discontinuation, but they differ on whether this represents a return to prior baseline disease activity versus a true rebound effect with disease activity more severe than prior to natalizumab initiation. ${ }^{70,74-79}$

Sorensen et al examined data for 375 natalizumabtreated MS patients taken from the Danish MS Treatment Registry who were treated with natalizumab for at least 24 weeks with 3-12 months of follow-up after natalizumab discontinuation. ${ }^{80}$ Overall, the mean ARR for the entire cohort after natalizumab discontinuation was lower than that prior to the initiation of natalizumab, but 83 patients $(22 \%)$ met the criteria for "rebound" of relapses defined as individual post-natalizumab relapse rate higher than their individual relapse rate prior to natalizumab therapy. ${ }^{80}$ Fagius et al studied 15 natalizumab-treated patients who 
stopped therapy as compared with 55 historical control patients on first-line DMT with cessation of therapy. ${ }^{81}$ The proportion of patients with relapses in the natalizumabtreated cohort was twice that of patients in the first-line DMT group $(P=0.013) .{ }^{81}$ Five of the natalizumab-treated patients exhibited "rebound" activity as defined in this study as relapse with larger EDSS increase or larger volume of gadolinium-enhancing lesions than ever seen in the individual patient. ${ }^{81}$ This study is limited, though, by its retrospective controls and significant differences between the two study groups, most notably a higher mean ARR in the natalizumab treatment group in the year prior to starting therapy $(2.3 \pm 1.2)$ compared with the first-line DMT group (ARR of $1.7 \pm 0.9$ ). ${ }^{81}$ The authors propose several hypotheses to explain the rebound phenomena including that the increase in circulating proinflammatory $\mathrm{CD}^{+}$and $\mathrm{CD}^{+} \mathrm{T}$ cells with natalizumab therapy leads to attack on the CNS when the drug is discontinued and there is removal of $\alpha 4$ integrin blockade. ${ }^{81}$ There is also speculation that natalizumab may have an "arresting effect" on the natural maturation of the immune system that typically causes MS patients to have a less inflammatory course in older age. ${ }^{81}$ Furthermore, there are case reports of significant rebound of MS disease activity after discontinuation of natalizumab with evidence of numerous gadolinium-enhancing lesions on MRI and severe relapses, including some that have been fatal. ${ }^{82-84}$

Contrary to these findings, several larger studies, including a randomized study of 175 patients randomized to continue or discontinue natalizumab ${ }^{75}$ and an observational prospective multicenter study including over 4,000 patients, ${ }^{85}$ failed to prove a true rebound effect. Rather, these studies demonstrate that patients are prone to return to pre-natalizumab disease activity levels upon its discontinuation. A Phase IIb study of 213 natalizumab-treated MS patients demonstrated return of gadolinium-enhancing lesions and relapses after treatment interruption, but no rebound activity was seen above the level in patients who received placebo. ${ }^{86}$ In addition, a large cohort of 1,866 natalizumab-treated patients from the AFFIRM, ${ }^{20}$ SENTINEL, ${ }^{22}$ and GLANCE ${ }^{87}$ trials were examined during treatment interruption when natalizumab was voluntarily removed from the market. ${ }^{74}$ During the at least 8 months of treatment interruption, disease activity never exceeded the levels observed in the placebo-treated subjects in the clinical trials. $^{74}$ This discussion of the possibility of rebound MS activity has also led to the consideration of optimal timing for initiation of the new DMT, which thus far favors a shorter washout interval. ${ }^{88}$

\section{Conclusion}

Natalizumab remains an important part of the treatment arsenal for patients with RRMS. It has proven to be highly efficacious in the reduction of clinical relapses and prevention of new MRI activity. Though generally well-tolerated, natalizumab does carry a risk for the life-threatening condition PML. Risk mitigation awareness and development of a formal monitoring program have encouraged careful prescribing of natalizumab, though the risk of PML has not been fully eliminated. Future work continues into the development of new biomarkers that may better predict an individual's risk of PML and further improve upon natalizumab's safety.

\section{Disclosure}

The authors report no conflicts of interest in this work.

\section{References}

1. Rice GP, Hartung HP, Calabresi PA. Anti-alpha4 integrin therapy for multiple sclerosis: mechanisms and rationale. Neurology. 2005;64(8): 1336-1342.

2. Shimonkevitz R, Colburn C, Burnham JA, Murray RS, Kotzin BL. Clonal expansions of activated gamma/delta $\mathrm{T}$ cells in recent-onset multiple sclerosis. Proc Natl Acad Sci U S A. 1993;90(3):923-927.

3. Skulina C, Schmidt S, Dornmair K, et al. Multiple sclerosis: braininfiltrating CD8+ T cells persist as clonal expansions in the cerebrospinal fluid and blood. Proc Natl Acad Sci U S A. 2004;101(8):2428-2433.

4. Butcher EC. Leukocyte-endothelial cell recognition: three (or more) steps to specificity and diversity. Cell. 1991;67(6):1033-1036.

5. Springer TA. Traffic signals for lymphocyte recirculation and leukocyte emigration: the multistep paradigm. Cell. 1994;76(2):301-314.

6. Pober JS, Gimbrone MA Jr, Lapierre LA, et al. Overlapping patterns of activation of human endothelial cells by interleukin 1, tumor necrosis factor, and immune interferon. J Immunol. 1986;137(6):1893-1896.

7. Heller RA, Kronke M. Tumor necrosis factor receptor-mediated signaling pathways. J Cell Biol. 1994;126(1):5-9.

8. Dustin ML, Rothlein R, Bhan AK, Dinarello CA, Springer TA. Induction by IL 1 and interferon-gamma: tissue distribution, biochemistry, and function of a natural adherence molecule (ICAM-1). J Immunol. 1986; 137:245-254.

9. Bochner BS, Luscinskas FW, Gimbrone MA Jr, et al. Adhesion of human basophils, eosinophils, and neutrophils to interleukin 1-activated human vascular endothelial cells: contributions of endothelial cell adhesion molecules. J Exp Med. 1991;173(6):1553-1557.

10. Lobb RR, Hemler ME. The pathophysiologic role of alpha 4 integrins in vivo. J Clin Invest. 1994;94(5):1722-1728.

11. Hemler ME, Elices MJ, Parker C, Takada Y. Structure of the integrin VLA-4 and its cell-cell and cell-matrix adhesion functions. Immunol Rev. 1990;114:45-65.

12. Damle NK, Aruffo A. Vascular cell adhesion molecule 1 induces T-cell antigen receptor-dependent activation of CD4+T lymphocytes. Proc Natl Acad Sci U S A. 1991;88(15):6403-6407.

13. Burkly LC, Jakubowski A, Newman BM, Rosa MD, Chi-Rosso G, Lobb RR. Signaling by vascular cell adhesion molecule-1 (VCAM-1) through VLA-4 promotes CD3-dependent T cell proliferation. Eur $J$ Immunol. 1991;21(11):2871-2875.

14. Wilkins JA, Stupack D, Stewart S, Caixia S. Beta 1 integrin-mediated lymphocyte adherence to extracellular matrix is enhanced by phorbol ester treatment. Eur J Immunol. 1991;21(2):517-522.

15. Dustin ML, Springer TA. T-cell receptor cross-linking transiently stimulates adhesiveness through LFA-1. Nature. 1989;341(6243):619-624. 
16. Guan JL, Hynes RO. Lymphoid cells recognize an alternatively spliced segment of fibronectin via the integrin receptor alpha 4 beta 1 . Cell. 1990;60(1):53-61.

17. Bayless KJ, Meininger GA, Scholtz JM, Davis GE. Osteopontin is a ligand for the alpha4beta1 integrin. $J$ Cell Sci. 1998;111(Pt 9): 1165-1174.

18. Barry ST, Ludbrook SB, Murrison E, Horgan CM. Analysis of the alpha4beta1 integrin-osteopontin interaction. Exp Cell Res. 2000; 258(2):342-351.

19. Yednock TA, Cannon C, Fritz LC, Sanchez-Madrid F, Steinman L, Karin N. Prevention of experimental autoimmune encephalomyelitis by antibodies against alpha 4 beta 1 integrin. Nature. 1992; 356(6364):63-66.

20. Polman CH, O'Connor PW, Havrdova E, et al. A randomized, placebocontrolled trial of natalizumab for relapsing multiple sclerosis. $N E n g l$ J Med. 2006;354(9):899-910.

21. Miller DH, Soon D, Fernando KT, et al. MRI outcomes in a placebocontrolled trial of natalizumab in relapsing MS. Neurology. 2007; 68(17):1390-1401.

22. Rudick RA, Stuart WH, Calabresi PA, et al. Natalizumab plus interferon beta-1a for relapsing multiple sclerosis. $N$ Engl J Med. 2006; 354(9):911-923.

23. Prosperini L, Fanelli F, Pozzilli C. Long-term assessment of no evidence of disease activity with natalizumab in relapsing multiple sclerosis. J Neurol Sci. 2016;364:145-147.

24. Steiner D. Natalizumab versus placebo in patients with secondary progressive multiple sclerosis (SPMS): results from ASCEND, a multicenter, double-blind, placebo-controlled, randomized phase 3 clinical trial. Paper presented at: American Academy of Neurology 2016 Annual Meeting; 2016; Vancouver, BC, Canada.

25. Ferenczy MW, Marshall LJ, Nelson CD, et al. Molecular biology, epidemiology, and pathogenesis of progressive multifocal leukoencephalopathy, the $\mathrm{JC}$ virus-induced demyelinating disease of the human brain. Clin Microbiol Rev. 2012;25(3):471-506.

26. Chesters PM, Heritage J, McCance DJ. Persistence of DNA sequences of BK virus and $\mathrm{JC}$ virus in normal human tissues and in diseased tissues. J Infect Dis. 1983;147(4):676-684.

27. Heritage J, Chesters PM, McCance DJ. The persistence of papovavirus BK DNA sequences in normal human renal tissue. J Med Virol. 1981; 8(2):143-150

28. Clifford DB, De Luca A, Simpson DM, Arendt G, Giovannoni G, Nath A. Natalizumab-associated progressive multifocal leukoencephalopathy in patients with multiple sclerosis: lessons from 28 cases. Lancet Neurol. 2010;9(4):438-446.

29. Tan IL, McArthur JC, Clifford DB, Major EO, Nath A. Immune reconstitution inflammatory syndrome in natalizumab-associated PML. Neurology. 2011;77(11):1061-1067.

30. Yousry TA, Pelletier D, Cadavid D, et al. Magnetic resonance imaging pattern in natalizumab-associated progressive multifocal leukoencephalopathy. Ann Neurol. 2012;72(5):779-787.

31. Berger JR, Aksamit AJ, Clifford DB, et al. PML diagnostic criteria: consensus statement from the AAN Neuroinfectious Disease Section. Neurology. 2013;80(15):1430-1438.

32. Mancuso R, Saresella M, Hernis A, et al. JC virus detection and JC virus-specific immunity in natalizumab-treated multiple sclerosis patients. J Transl Med. 2012;10:248.

33. Amend KL, Turnbull B, Foskett N, Napalkov P, Kurth T, Seeger J. Incidence of progressive multifocal leukoencephalopathy in patients without HIV. Neurology. 2010;75(15):1326-1332.

34. Bloomgren G, Richman S, Hotermans C, et al. Risk of natalizumabassociated progressive multifocal leukoencephalopathy. $N$ Engl J Med. 2012;366(20):1870-1880.

35. Bozic C, Richman S, Plavina T, et al. Anti-John Cunningham virus antibody prevalence in multiple sclerosis patients: baseline results of STRATIFY-1. Ann Neurol. 2011;70:742-750.

36. O'Connor P, Goodman A, Kappos L, et al. Long-term safety and effectiveness of natalizumab redosing and treatment in the STRATA MS study. Neurology. 2014;83(1):78-86.
37. Bozic C, Richman S, Plavina T, et al. Anti-JCV Antibody prevalence in patients with relapsing multiple sclerosis receiving or considering treatment with natalizumab: baseline results of STRATIFY-2 (S41.002). Neurology. 2012;78(1 Supplement):S41.002.

38. Plavina T, Subramanyam M, Bloomgren G, et al. Anti-JC virus antibody levels in serum or plasma further define risk of natalizumabassociated progressive multifocal leukoencephalopathy. Ann Neurol. 2014;76(6):802-812.

39. Borchardt J, Berger JR. Re-evaluating the incidence of natalizumabassociated progressive multifocal leukoencephalopathy. Mult Scler Relat Disord. 2016;8:145-150.

40. Grewal IS, Foellmer HG, Grewal KD, et al. CD62L is required on effector cells for local interactions in the CNS to cause myelin damage in experimental allergic encephalomyelitis. Immunity. 2001;14(3): 291-302.

41. Huang K, Kikuta A, Rosen SD. Myelin localization of a central nervous system ligand for L-selectin. J Neuroimmunol. 1994;53(2):133-141.

42. Basnyat P, Hagman S, Kolasa M, et al. Association between soluble L-selectin and anti-JCV antibodies in natalizumab-treated relapsingremitting MS patients. Mult Scler Relat Disord. 2015;4(4):334-338.

43. Wedepohl S, Beceren-Braun F, Riese S, et al. L-selectin-a dynamic regulator of leukocyte migration. Eur J Cell Biol. 2012;91(4):257-264.

44. Wang Y, Zhang AC, Ni Z, Herrera A, Walcheck B. ADAM17 activity and other mechanisms of soluble L-selectin production during death receptor-induced leukocyte apoptosis. J Immunol. 2010;184(8): 4447-4454.

45. Palecanda A, Walcheck B, Bishop DK, Jutila MA. Rapid activationindependent shedding of leukocyte L-selectin induced by cross-linking of the surface antigen. Eur J Immunol. 1992;22(5):1279-1286.

46. Ivetic A. Signals regulating L-selectin-dependent leucocyte adhesion and transmigration. Int J Biochem Cell Biol. 2013;45(3):550-555.

47. Schleiffenbaum B, Spertini O, Tedder TF. Soluble L-selectin is present in human plasma at high levels and retains functional activity. $J$ Cell Biol. 1992;119(1):229-238.

48. Raffler NA, Rivera-Nieves J, Ley K. L-selectin in inflammation, infection and immunity. Drug Discov Today Ther Strateg. 2005;2(3):213-220.

49. Smalley DM, Ley K. L-selectin: mechanisms and physiological significance of ectodomain cleavage. J Cell Mol Med. 2005;9(2):255-266.

50. Pignolet B, Schwab N, Schneider-Hohendorf T, et al. CD62L test at 2 years of natalizumab predicts progressive multifocal leukoencephalopathy. Neurology. 2016;87(23):2491-2494.

51. Outteryck O, Ongagna JC, Brochet B, et al. A prospective observational post-marketing study of natalizumab-treated multiple sclerosis patients: clinical, radiological and biological features and adverse events. The BIONAT cohort. Eur J Neurol. 2014;21(1):40-48.

52. Lieberman LA, Zeng W, Singh C, et al. CD62L is not a reliable biomarker for predicting PML risk in natalizumab-treated R-MS patients. Neurology. 2016;86(4):375-381.

53. Villar LM, Costa-Frossard L, Masterman T, et al. Lipid-specific immunoglobulin $\mathrm{M}$ bands in cerebrospinal fluid are associated with a reduced risk of developing progressive multifocal leukoencephalopathy during treatment with natalizumab. Ann Neurol. 2015;77(3):447-457.

54. Khatri BO, Man S, Giovannoni G, et al. Effect of plasma exchange in accelerating natalizumab clearance and restoring leukocyte function. Neurology. 2009;72(5):402-409.

55. Zhovtis Ryerson L, Frohman TC, Foley J, et al. Extended interval dosing of natalizumab in multiple sclerosis. $J$ Neurol Neurosurg Psychiatry. 2016;87(8):885-889.

56. Dong-Si T, Gheuens S, Gangadharan A, et al. Predictors of survival and functional outcomes in natalizumab-associated progressive multifocal leukoencephalopathy. J Neurovirol. 2015;21(6):637-644.

57. Ghezzi A, Grimaldi LM, Marrosu MG, et al. Natalizumab therapy of multiple sclerosis: recommendations of the Multiple Sclerosis Study Group - Italian Neurological Society. Neurol Sci. 2011;32(2): 351-358.

58. Hodecker SC, Sturner KH, Becker V, et al. Maraviroc as possible treatment for PML-IRIS in natalizumab-treated patients with MS. Neurol Neuroimmunol Neuroinflamm. 2017;4(2):e325. 
59. Giacomini PS, Rozenberg A, Metz I, Araujo D, Arbour N, Bar-Or A. Maraviroc and JC virus-associated immune reconstitution inflammatory syndrome. N EnglJ Med. 2014;370(5):486-488.

60. Landi D, De Rossi N, Zagaglia S, et al. No evidence of beneficial effects of plasmapheresis in natalizumab-associated PML. Neurology. 2017;88(12):1144-1152.

61. Maloney E, Molloy A, Al Hussona M, O’Donnell L, Killeen R, McGuigan C. Natalizumab-associated progressive multifocal leukoencephalopathy: successful treatment without plasma exchange and its associated risks. J Neurol. 2017;264(2):401-403.

62. Biogen. Tysabri (natalizumab) injection, for intravenous use. Full prescribing information. Revised May 2016. Available from: www. tysabri.com/prescribinginfo. Accessed February 27, 2017.

63. Shenoy ES, Mylonakis E, Hurtado RM, Venna N. Natalizumab and HSV meningitis. J Neurovirol. 2011;17(3):288-290.

64. Kwiatkowski A, Gallois J, Bilbault N, Calais G, Mackowiak A, Hautecoeur P. Herpes encephalitis during natalizumab treatment in multiple sclerosis. Mult Scler. 2012;18(6):909-911.

65. Sharma K, Ballham SA, Inglis KE, Renowden S, Cottrell DA. Does natalizumab treatment increase the risk of herpes simplex encephalitis in multiple sclerosis? Case and discussion. Mult Scler Relat Disord. 2013;2(4):385-387.

66. Fragoso YD, Brooks JB, Gomes S, de Oliveira FT, da Gama PD. Report of three cases of herpes zoster during treatment with natalizumab. CNS Neurosci Ther. 2013;19(4):280-281.

67. Delbue S, Comar M, Ferrante P. Natalizumab treatment of multiple sclerosis: new insights. Immunotherapy. 2017;9(2):157-171.

68. Friend S, Richman S, Bloomgren G, Cristiano LM, Wenten M. Evaluation of pregnancy outcomes from the Tysabri(R) (natalizumab) pregnancy exposure registry: a global, observational, follow-up study. BMC Neurol. 2016;16(1):150.

69. Vennegoor A, van Rossum JA, Leurs C, et al. High cumulative JC virus seroconversion rate during long-term use of natalizumab. Eur J Neurol. 2016;23(6):1079-1085.

70. Gueguen A, Roux P, Deschamps R, et al. Abnormal inflammatory activity returns after natalizumab cessation in multiple sclerosis. J Neurol Neurosurg Psychiatry. 2014;85(9):1038-1040.

71. Vellinga MM, Castelijns JA, Barkhof F, Uitdehaag BM, Polman CH. Postwithdrawal rebound increase in T2 lesional activity in natalizumabtreated MS patients. Neurology. 2008;70(13 Pt 2):1150-1151.

72. Miravalle A, Jensen R, Kinkel R. Immune reconstitution inflammatory syndrome in patients with multiple sclerosis following cessation of natalizumab therapy. Arch Neurol. 2011;68(2):186-191.

73. Killestein J, Vennegoor A, Strijbis EM, et al. Natalizumab drug holiday in multiple sclerosis: poorly tolerated. Ann Neurol. 2010;68(3): 392-395.
74. O'Connor PW, Goodman A, Kappos L, et al. Disease activity return during natalizumab treatment interruption in patients with multiple sclerosis. Neurology. 2011;76(22):1858-1865.

75. Fox RJ, Cree BA, De Seze J, et al. MS disease activity in RESTORE: a randomized 24-week natalizumab treatment interruption study. Neurology. 2014;82(17):1491-1498.

76. Havla J, Gerdes LA, Meinl I, et al. De-escalation from natalizumab in multiple sclerosis: recurrence of disease activity despite switching to glatiramer acetate. J Neurol. 2011;258(9):1665-1669.

77. West TW, Cree BA. Natalizumab dosage suspension: are we helping or hurting? Ann Neurol. 2010;68(3):395-399.

78. Rossi S, Motta C, Studer V, et al. Effect of glatiramer acetate on disease reactivation in MS patients discontinuing natalizumab. Eur J Neurol. 2013;20(1):87-94.

79. Sangalli F, Moiola L, Ferre L, et al. Long-term management of natalizumab discontinuation in a large monocentric cohort of multiple sclerosis patients. Mult Scler Relat Disord. 2014;3(4):520-526.

80. Sorensen PS, Koch-Henriksen N, Petersen T, Ravnborg M, Oturai A, Sellebjerg F. Recurrence or rebound of clinical relapses after discontinuation of natalizumab therapy in highly active MS patients. J Neurol. 2014;261(6):1170-1177.

81. Fagius J, Feresiadou A, Larsson EM, Burman J. Discontinuation of disease modifying treatments in middle aged multiple sclerosis patients. First line drugs vs natalizumab. Mult Scler Relat Disord. 2017;12: $82-87$.

82. Rigau V, Mania A, Béfort P, et al. Lethal multiple sclerosis relapse after natalizumab withdrawal. Neurology. 2012;79(22):2214-2216.

83. Daelman L, Maitrot A, Maarouf A, Chaunu M, Papeix C, Tourbah A. Severe multiple sclerosis reactivation under fingolimod 3 months after natalizumab withdrawal. Mult Sclers J. 2012;18(11):1647-1649.

84. Baumgartner A, Stich O, Rauer S. Clinical and radiological disease reactivation after cessation of long-term therapy with natalizumab. Int J Neurosci. 2012;122(1):35-39.

85. Papeix C, Vukusic S, Casey R, et al. Risk of relapse after natalizumab withdrawal: Results from the French TYSEDMUS cohort. Neurol Neuroimmunol Neuroinflamm. 2016;3(6):e297.

86. Miller DH, Khan OA, Sheremata WA, et al. A controlled trial of natalizumab for relapsing multiple sclerosis. $N$ Engl J Med. 2003;348(1): $15-23$.

87. Goodman AD, Rossman H, Bar-Or A, et al. GLANCE: results of a phase 2, randomized, double-blind, placebo-controlled study. Neurology. 2009;72(9):806-812.

88. Kappos L, Radue EW, Comi G, et al. Switching from natalizumab to fingolimod: A randomized, placebo-controlled study in RRMS. Neurology. 2015;85(1):29-39.
Neuropsychiatric Disease and Treatment

\section{Publish your work in this journal}

Neuropsychiatric Disease and Treatment is an international, peerreviewed journal of clinical therapeutics and pharmacology focusing on concise rapid reporting of clinical or pre-clinical studies on a range of neuropsychiatric and neurological disorders. This journal is indexed on PubMed Central, the 'PsycINFO' database and CAS,
Dovepress

and is the official journal of The International Neuropsychiatric Association (INA). The manuscript management system is completely online and includes a very quick and fair peer-review system, which is all easy to use. Visit http://www.dovepress.com/testimonials.php to read real quotes from published authors. 